\title{
Oral Mucosal Lesions in Psoriasis Patients: A Hospital Based Study
}

\author{
Abhishek Kumar Jha ${ }^{1}$ \\ ${ }^{1}$ Assistant Professor, Department of Dermatology, Patna medical College and Hospital, Patna, Bihar, India
}

\section{Abstract}

Background: Oral lesions in dermatological diseases may be the early aspects of any disease manifestation and occasionally lesions occur simultaneously in the skin as well as mucous membrane. Subjects and Methods: The present work was designed as a prospective tertiary urban hospital based, case control study during the period from February 2018 to January 2019. The association between studied variables was calculated using descriptive statistics tests such as Chi-squared test and Fisher's exact test, and $\mathrm{P}<0.05$ was considered statistically significant. Results: A total of 120 psoriasis patients, 55 males (45.88\%) and 65 females $(54.16 \%)$ were included in the study. The age of the patients ranged from 5 years to 56 years (mean age 24.6 years). The most common form of psoriasis was chronic plaque form (Psoriasis Vulgaris) observed in 85 cases. The majority of patients $(72.56 \%)$ were suffering from a mild form of the disease. Psoriasis Area and Severity Index (PASI) score of most patients (72.56\%) were below 10. The oral lesion was seen in 31 cases (25.83\%) of which fissured tongue and geographic tongue were the most common oral lesions identified. Of total 100 psoriatic patients, 45 cases were male, and 55 were female. Mean age of patients was 37.71 years. observed in 85 cases. The majority of patients (70 \%) were suffering from a mild form of the disease. Psoriasis Area and Severity Index (PASI) score of most patients were below. Conclusion: The present study highlights the prevalence of oral lesions such as fissured tongue and geographic tongue is higher in psoriatic patients.

Keywords: Oral lesion, psoriasis, fissured and geographical tongue.

Corresponding Author: Dr. Abhishek Kumar Jha, Assistant Professor, Department of Dermatology, Patna medical College and Hospital, Patna, Bihar, India.

Received: April 2019

Accepted: May 2019

\section{Introduction}

Oral lesions in dermatological diseases may be the early aspects of any disease manifestation and occasionally lesions occur simultaneously in the skin as well as mucous membrane. Geographic tongue is an asymptomatic inflammatory disorder of the tongue mucosa of unknown etiology and is characterized by circinate, erythematous, ulcer-like lesions of the dorsum and lateral border of the tongue due to loss of filiform papillae of the tongue epithelium. It is also referred by various terminologies such as benign migratory glossitis, erythema migrans, annulus migrans and wandering rash of the tongue. Lateral margins and tip of the tongue are the most commonly involved sites followed by dorsal and ventral surfaces. Periods of remission and exacerbation of varying duration are usually evident. The lesion recurs in the new locations thereby producing the migrating pattern. Continuously changing patterns and migration of lesions on the tongue surface with unusual appearance of the tongue are the usual chief complaints of the patient. It can occur either as isolated or multiple lesions, can be asymptomatic or present with symptoms like pain, burning sensation, discomfort, dysgeusia, sensitivity to hot, spicy and sour food, pain in ears or ipsilateral submandibular lymphadenopathy. Majority of the patients will be asymptomatic.

Histopathological examination reveals a thick keratin layer infiltrated by mixed inflammatory cell infiltrate, thin elongated rete ridges and epithelial oedema. The inflammatory cells produce small micro abscesses called Monro's abscesses in the keratin and spinous layer. Superficial areas may reveal candidal hyphae and spores. Areas corresponding to the red patches show increased oedema, acanthotic epithelium and complete absence of filiform papillae. The areas from the centre of the atrophic areas show complete absence of filiform papillae and parakeratotic layers. The elevated white borders include subepithelial infiltration of neutrophils, micro abscesses, leukocyte invasion into the epithelium, intraepithelial oedema, acantholysis, glycogen deposits in the epithelial cells and exfoliation of necrotic cells in the surface layer. Histopathological examination is only rarely needed for atypical cases as the clinical diagnosis is evident by migratory pattern of lesion, circinate aspect and mild pain. Although the main etiology of geographic tongue remains unknown, some factors including emotional stress, vitamin deficiency, allergy, genetic factors, immune disorders, bacterial or fungal infection and systemic diseases are known to play a causative role. Geographic tongue is commonly associated with many systemic diseases such as atopy, allergy, stress, anaemia, gastrointestinal disturbances and hormonal variations, syndromes like Reiter's syndrome, Down syndrome, Aarskog syndrome, Fetal hydantoin syndrome and Robinow's syndrome. Our study was aimed to determine the association of oral lessions with psoriasis. 
Geographic tongue typically does not require any treatment if asymptomatic. If there is excessive pain and discomfort, medications like analgesics such as acetoaminophen, antiinflammatory drugs, antihistamines like diphenhydramine hydrochloride, mouth rinses with topical anaesthetics like lidocaine gel, topical corticosteroids like betamethosone, cyclosporine, tretinion, zinc and vitamin K2 supplements can be advised. Topical Tacrolimus application has been effective in recalcitrant cases. The present work was conducted for the purpose of evaluating association of oral lesions in psoriasis patients.

\section{Subjects and Methods}

The present work was designed as a prospective tertiary urban hospital based, case control study during the period from February 2018 to January 2019. Psoriasis patients attending the dermatologic out-patient were enrolled. All patients were examined for the presence of oral lesions, and the clinical and epidemiological features of the disease were recorded in a questionnaire for each patient. Furthermore, the degree of erythema, thickness, scaling of and extension of involved area in different parts of the body of patients were calculated based on Psoriasis Area and Severity Index (PASI) score and recorded in the medical records of the patients. Biopsy was taken from atypical suspected patients with oral lesions for diagnostic confirmation. The association between studied variables was calculated using descriptive statistics tests such as Chi-squared test and Fisher's exact test, and $\mathrm{P}<0.05$ was considered statistically significant.

\section{Results}

A total of 120 psoriasis patients, 55 males (45.88\%) and 65 females $(54.16 \%)$ were included in the study. The age of the patients ranged from 5 years to 56 years (mean age 24.6 years). The most common form of psoriasis was chronic plaque form (Psoriasis Vulgaris) observed in 85 cases. The majority of patients $(72.56 \%)$ were suffering from a mild form of the disease. Psoriasis Area and Severity Index (PASI) score of most patients (72.56\%) were below 10. The oral lesion was seen in 31 cases $(25.83 \%)$ of which fissured tongue and geographic tongue were the most common oral lesions identified. [Table 1]

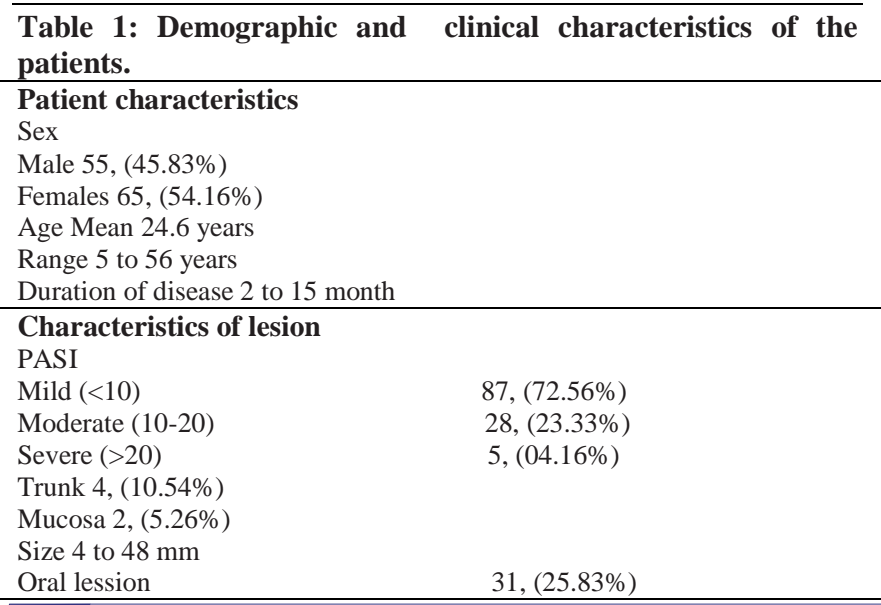

\section{Discussion}

Psoriasis is a common skin disorder and its review of literature shows that oral mucosa involvement among psoriatic patients is relatively rare. The prevalence of oral lesions in this study was $31 \%$. We found no significant relationship between the presences of oral lesions in psoriatic patients with sex. Similar result was reported by Taheri et al. ${ }^{[1]}$ In our study the two most common oral anomalies found to be associated with psoriasis turned out to be fissured tongue and geographic tongue. Fissured tongue is a developmental anomaly of the tongue dorsum most often associated with geographic tongue and is also increased in psoriasis. The results of a literature review showed that the prevalence of fissured tongue was ranging from $9.8 \%$ to $47.5 \%$ and of the geographic tongue was between $5.6 \%$ and $18.1 \%{ }^{[2]}$ A study by Tomb et al. also showed that there was a strong correlation between psoriasis and geographic tongue. DaneshPazhooh et al. in their investigation reported that $32 \%$ of patients with psoriasis and geographic tongue had severe psoriasis, which can be indicated as a correlation between this lesion and severity of the disease. ${ }^{[3]}$ In a study conducted by Zargari et al., Geographic tongue was observed in $7 \%$ of patients with early psoriasis and $1 \%$ of patients with late psoriasis and that the incidence of geographic tongue in early psoriasis might be indicated the severity of the disease ${ }^{[4]}$ Although the main etiology of geographic tongue remains unknown, some factors including emotional stress, vitamin deficiency, allergy, genetic factors, immune disorders, bacterial or fungal infection and systemic diseases are known to play a causative role. Siblings of one parent affected by geographic tongue revealed significantly higher prevalence of geographic tongue than those siblings of unaffected parents suggesting the role of familial and hereditary factors. ${ }^{[5]}$ Assessment of histocompatibility antigens among these patients revealed significantly increased DR5 and DRW6 antigens in their serum when compared to controls while DR2 was reduced comparatively. ${ }^{[6,7]}$

Geographic tongue is commonly associated with other systemic disease associations such as atopy, allergy, stress, anaemia, gastrointestinal disturbances and hormonal variations can also be present. ${ }^{[8,9]}$ It may also be associated with syndromes like Reiter's syndrome, Down syndrome, Aarskog syndrome, Fetal hydantoinsyndrome and Robinow's syndrome. ${ }^{[10-13]}$ Psychosomatic factors appear to have a significant role in its etiology. Redman et al. demonstrated higher prevalence of geographic tongue in mentally ill patients. ${ }^{[14]}$

Geographic tongue typically does not require any treatment if asymptomatic. Periodic follow up to confirm diagnosis is required in case of first visit and when history is unclear. Reassure the patient about the benign and self-limiting nature of the lesion. If there is excessive pain and discomfort, medications like analgesics such as acetoaminophen, anti-inflammatory drugs, antihistamines like diphenhydramine hydrochloride, mouth rinses with topical anaesthetics like lidocaine gel, topical 
corticosteroids like betamethosone, cyclosporine, tretinion, zinc and vitamin K2 supplements can be advised. ${ }^{[15-17]}$ Topical Tacrolimus application has been effective in recalcitrant cases. ${ }^{[18]}$ Satisfactory improvement was observed by systemic administration of cyclosporine microemulsion pre-concentrate, with initial dose of $3 \mathrm{mg} / \mathrm{kg} / \mathrm{day}$ and maintenance dose of $1.5 \mathrm{mg} / \mathrm{kg} / \mathrm{day}$ two months later. ${ }^{[19]}$

\section{Conclusion}

In conclusion, the prevalence of oral lesions such as fissured tongue and geographic tongue is higher in psoriatic patients suggests further studies for approving the clinical importance of these apparently nonspecific lesions as possible predictors of the severity of psoriasis.

\section{References}

1. Perez FH, Avelda-ez AJ, Ruvalcaba MD, Barcelot MD, Camacho ME, Memije ME, Taylor AM. Prevalence of oral lesions in patients with psoriasis. Med Oral Patol Oral Cir Bucal. 2008;1(13):703-8.

2. Picciani BL, Domingos TA, Teixeira-Souza T, Santos VD, Gonzaga HF, Cardoso-Oliveira J, Gripp AC, Dias EP, Carneiro S. Geographic tongue and psoriasis:clinical, histopathological, immunohistochemical and genetic correlation-a literature review. Anais brasileiros de dermatologia. 2016;91(4):410-21.

3. Daneshpazhooh M, Mosleh H, Akhyani M, Etesami M. Tongue lesions in psoriasis:a controlled study. BMC Dermatology. 2004;4(16):1-4.

4. Zargari $O$. The prevalence and significance of fissured tongue and geographical tongue in psoriatic patients. 2006;31(2):192-5.

5. Assimakopoulos D, Patrikakos G, Fotika C, Elisaf M. Benign migratory glossitis or geographic tongue: an enigmatic oral lesion. Am J Med. 2002;113:751-755.

6. Eidelman E, Chosack A, Cohen T. Scrotal tongue and geographic tongue: polygeneic and associated triats. Oral Surg Oral Med Oral Pathol. 1976;42:591-96.

7. Hooda A, Rathee M, Gulia JS, Yadav SPS. Benign migratory glossitis: a review. The Internet Journal of Family Practice. 2011;9(2):1528-8358.

8. Cerqueira DF, de Souza IP. Orofacial manifestation of a patient with Robinow's syndrome. A case report in paediatric patient. Oral Surg Oral Med Oral Pathol Oral RadiolEndod. 2008;105:353-57.

9. Jainkittivong A, Lanlais RP. Geographic tongue: clinical characteristics of 188 cases. J Contemp Dent Pract. 2005;1:123-35.

10. Daneshpazhooh M, Mosleh H, Akhyani M, Etesami M. Tongue lesions in psoriasis:a controlled study. BMC Dermatology. 2004;4(16):1-4.

11. Redman RS. Prevalence of geographic tongue, fissured tongue, median rhomboid glossitis and hairy tongue among 3611 Minnesota school children. Oral Path. 1970;30:390-98.

12. Regezi JA, Sciubba JJ. Oral Pathology. Clinico-Pathologic correlations. Philadelphia: WB Saunders; 1993. pp. 150-151.

13. Desai VD, Baghla P. Asymptomatic reversible lesion on tongue - case series in paediatric patients. J Adv Med Dent Scie. 2014;2(2):176-79.

14. Plackova A, Skach M. The ultrastructure of geographic tongue. Oral Surg Oral Med Oral Pathol. 1975;40:760-68.

15. Picciani B, Silva-Junior G, Carneiro S, Sampaio AL, Goldemberg DC, Oliveira J, et al. Geographic stomatitis: an oral manifestation of psoriasis? J Dermatol Case Rep. 2012;6:113-16.

16. Helfman RJ. The treatment of geographic tongue with topical retin-A solution. Cutis. 1975;50:41-46.

17. Gibson J, et al. Geographic tongue: The clinical response to zinc supplementation. J Trace Elem Experim Med. 1990;3:203-08.

18. Ravi Prakash SM, Sankalp V, Rajendra P, Udita S. Tacrolimus: a novel approach against wandering rash- A pilot study. SPJTS. 2014;2(1):26973.

19. Abe M, Sogabe Y, Syuto T, Ishibuchi H, Yokoyama Y, Ishikawa O. Successful treatment with cyclosporine administration for persistent benign migratory glossitis. J Dermatol. 2007;34:340-43

Copyright: () the author(s), 2019. It is an open-access article distributed under the terms of the Creative Commons Attribution License (CC BY 4.0), which permits authors to retain ownership of the copyright for their content, and allow anyone to download, reuse, reprint, modify, distribute and/or copy the content as long as the original authors and source are cited.

How to cite this article: Jha AK. Oral Mucosal Lesions in Psoriasis Patients: A Hospital Based Study. Asian J. Med. Res. 2019;8(2):DT05DT07.

DOI: dx.doi.org/10.21276/ajmr.2019.8.2.DT2

Source of Support: Nil, Conflict of Interest: None declared. 